Case Report

\title{
De Novo CD5 Negative Blastic Mantle Cell Lymphoma Presented with Massive Bone Marrow Necrosis without Adenopathy or Organomegaly
}

\author{
Ghaleb Elyamany, ${ }^{1,2}$ Ali Matar Alzahrani, ${ }^{3}$ Eman Al Mussaed, ${ }^{4}$ Hassan Aljasem, ${ }^{5}$ \\ Sultan Alotaibi, ${ }^{5}$ and Hatem Elghezal ${ }^{1,2}$ \\ ${ }^{1}$ Department of Central Military Laboratory and Blood Bank, Prince Sultan Military Medical City, P.O. Box 7897, \\ Riyadh 11159, Saudi Arabia \\ ${ }^{2}$ Department of Hematology and Blood Bank, Theodor Bilharz Research Institute, Giza, Egypt \\ ${ }^{3}$ Department of Oncology, Prince Sultan Military Medical City, P.O. Box 7897, Riyadh 11159, Saudi Arabia \\ ${ }^{4}$ Department of Basic Science, Princess Nourah Bint Abdulrahman University, College of Medicine, Riyadh, Saudi Arabia \\ ${ }^{5}$ Department of Adult Clinical Hematology and Stem Cell Therapy, Prince Sultan Military Medical City, P.O. Box 7897, \\ Riyadh 11159, Saudi Arabia \\ Correspondence should be addressed to Ghaleb Elyamany; ghalebelyamany@yahoo.com
}

Received 14 April 2015; Revised 12 July 2015; Accepted 26 July 2015

Academic Editor: John Frater

Copyright (C) 2015 Ghaleb Elyamany et al. This is an open access article distributed under the Creative Commons Attribution License, which permits unrestricted use, distribution, and reproduction in any medium, provided the original work is properly cited.

\begin{abstract}
The recent World Health Organization (WHO) classification defines mantle cell lymphoma (MCL) as a distinct entity characterized by a unique immunophenotype and a molecular hallmark of chromosomal translocation $\mathrm{t}(11 ; 14)$ (q13;q32). We report an unusual case of an advanced stage of CD5 negative MCL with a blastoid variant with a massive bone marrow (BM) necrosis as an initial presenting feature, with no adenopathy or hepatosplenomegaly. The pathologic features showed blastoid variant of MCL and flow cytometry showed that the tumor cells were CD5-, CD19+, CD20+, FMC-7+, CD23-, and lambda light chain restricted. Chromosomal analysis, using karyotype and fluorescent in situ hybridization (FISH), demonstrated karyotypic abnormalities in addition to the $\mathrm{t}(11 ; 14)$. Our case study may be reported as a unique case of CD5- blastic MCL with unusual presentation and findings which made the diagnosis of MCL difficult.
\end{abstract}

\section{Introduction}

Mantle cell lymphoma (MCL) is a relatively rare non-Hodgkin's lymphoma (NHL) with a heterogeneous clinical presentation comprising about $3 \%$ to $10 \%$ of NHL cases [1].

Diagnosis is based on lymph node, bone marrow, or tissue morphology of centrocytic lymphocytes, small cell type, or blastoid variant cells. Chromosomal translocation $t(11 ; 14)$ is the molecular hallmark of MCL; it is considered to be the primary molecular event in juxtaposing the CCND1 gene (11q13) with the IgH gene (14q32) and results in the overexpression of cyclin D1 [2-4]. Although cyclin D1 activation may not be sufficient to induce malignant transformation and additional deregulation of other oncogenes, it is required for lymphoma development. The study of a large series of cytogenetic profiles of MCL revealed that in most cases $t(11 ; 14)$ is associated with numerous structural and numerical alterations of chromosomes considered as secondary rearrangements. The most frequent abnormalities involve chromosomes 1, 7, 11, and $13[5,6]$. Molecular genetic studies have demonstrated that deletions of 1p21-22, 13q14, and 11q22-q23 are the most common clonal genomic aberrations in the majority of MCL $[6,7]$.

MCL has characteristics of both indolent and aggressive lymphomas. Because of its aggressive clinical course, MCL identification is important; it has a median survival of 3-5 


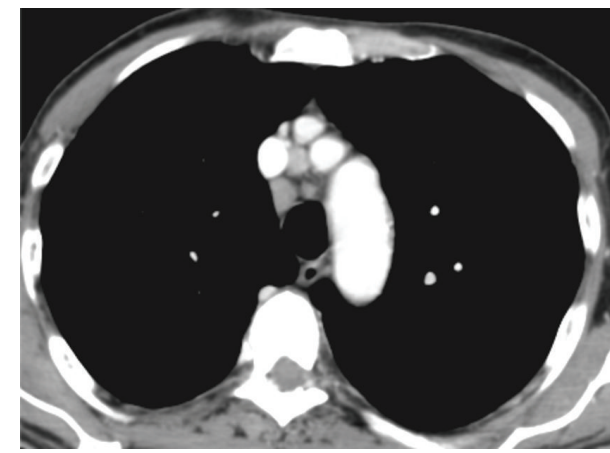

(a)

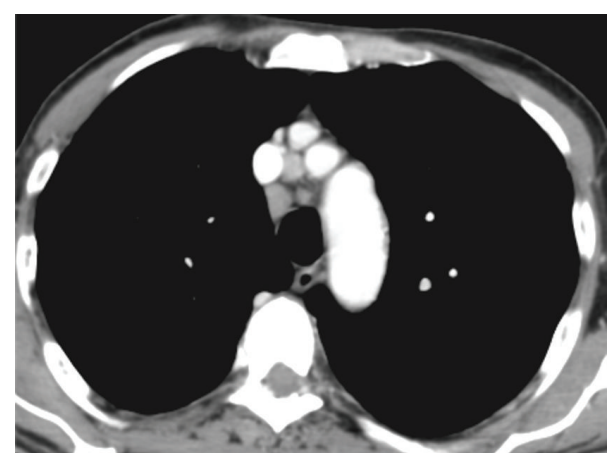

(b)

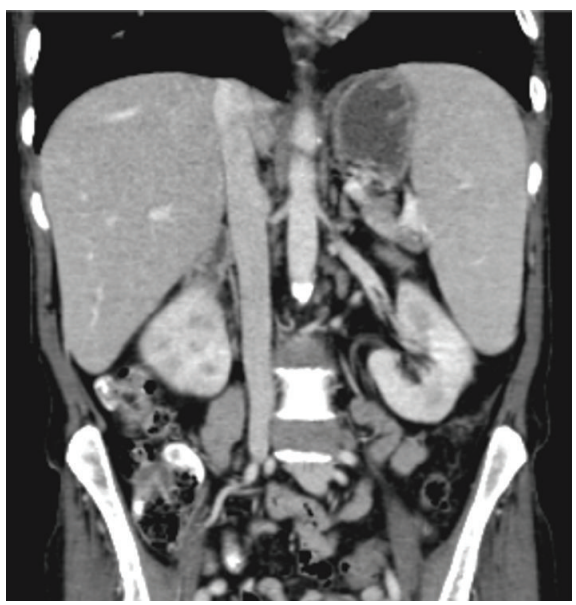

(c)

Figure 1: Axial postcontrast CT of the chest ((a) and (b)) shows minimally enlarged mediastinal lymph nodes; the largest one in the right pretracheal region measures about $12.3 \times 11.1 \mathrm{~mm}$. Coronal postcontrast CT of the abdomen (c) shows mildly enlarged spleen and liver measuring about 14.5 and $15.7 \mathrm{~cm}$, respectively, without evidence of focal lesions or associated abdominal lymphadenopathy.

years [3]. The first line of therapy for MCL is the commonly used regimen of rituximab in combination with chemotherapy and it has a total efficiency of $75 \%-96 \%[8,9]$.

Here, we describe an unusual case of advanced-stage blastic MCL with a massive BM necrosis as an initial presenting feature with no adenopathy or hepatosplenomegaly (HSM). Chromosomal analysis using karyotype and fluorescent in situ hybridization (FISH) demonstrated complex karyotypic abnormalities in addition to the $\mathrm{t}(11 ; 14)$.

\section{Case Presentation}

A 64-year-old male patient, smoker with chronic obstructive airway disease, on bronchodilators, presented with generalized body pain, bilateral lower limb and low back pain, night sweats, anorexia, and weight loss of $25 \mathrm{~kg}$ in 6 weeks. He had no fever or chills. By physical examination the patient looked ill and cachectic but had no adenopathy, HSM, or skin lesions.

A complete blood count revealed anemia (hemoglobin $10.3 \mathrm{gm} / \mathrm{dL})$, thrombocytopenia $\left(90 \times 10^{9} / \mathrm{L}\right)$, and mild leukocytosis $\left(12.1 \times 10^{9} / \mathrm{L}\right)$ with absolute monocytosis. A peripheral blood film showed no atypical/abnormal lymphocytes, but $1 \%$ nucleated RBCs were detected. The white blood cell differential count was neutrophils 7.1, lymphocytes 3.1, monocytes
1.8, basophils 0.1 , and eosinophils 0.0. A computerized tomography scan of the chest, abdomen, and pelvis revealed minimally enlarged mediastinal lymph nodes; the largest one in the right pretracheal region measured about $12.3 \times 11.1 \mathrm{~mm}$; mildly enlarged spleen and liver measured about 14.5 and $15.7 \mathrm{~cm}$, respectively, without evidence of focal lesions or associated abdominal lymphadenopathy (Figure 1).

The first BM smears and biopsy were stained with WrightGiemsa stain and hematoxylin and eosin and revealed massive BM necrosis (Figures 2(a) and 2(b)). Flow cytometry on peripheral blood (PB) showed no evidence of leukemia or lymphoma involving PB (data not shown). The second BM biopsy revealed hypercellular marrow due to a diffuse abnormal malignant lymphoid infiltrate and areas of necrosis. Morphologically, the neoplastic cells showed atypical large cells with regular or slightly indented nuclei, dispersed chromatin, abundant agranular cytoplasm, and prominent nucleoli (blast-like cells) with starry-sky appearance (Figures 2(c) and 2(d)). Immunophenotyping by flow cytometry revealed a discrete lymphoid population (bright CD45 and low side scatter) that expressed CD19, CD20, CD22, FMC-7 (45\%), and monotypic lambda light chain but was negative for CD5, CD10, CD23, and CD34 (Figure 3; some data are not shown). The immunohistochemistry (IHC) was performed (Ventana 


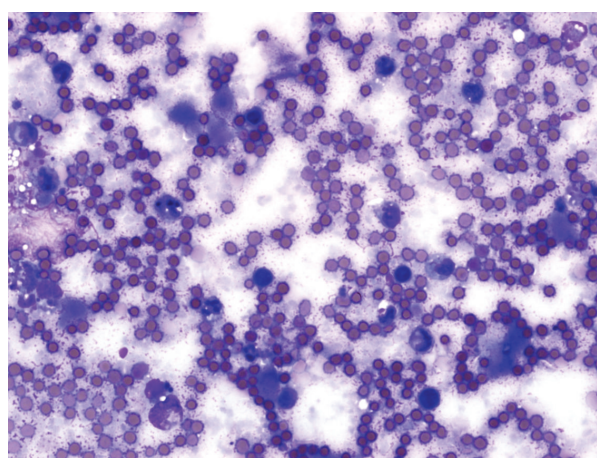

(a)

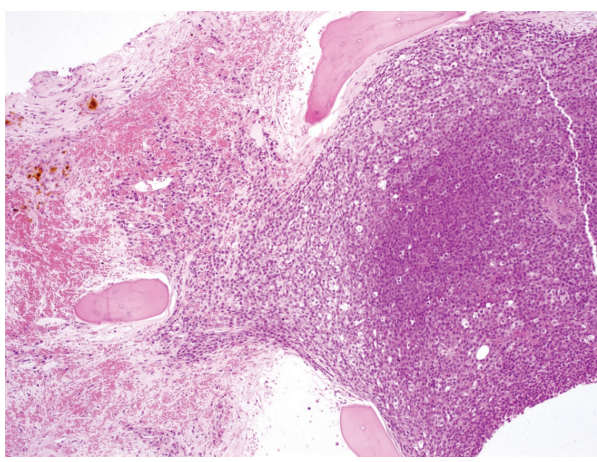

(c)

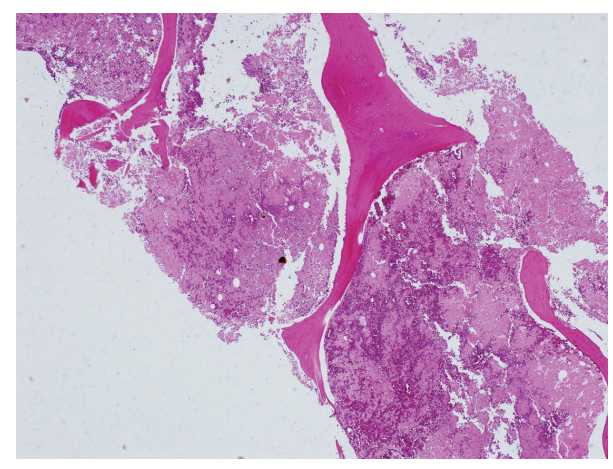

(b)

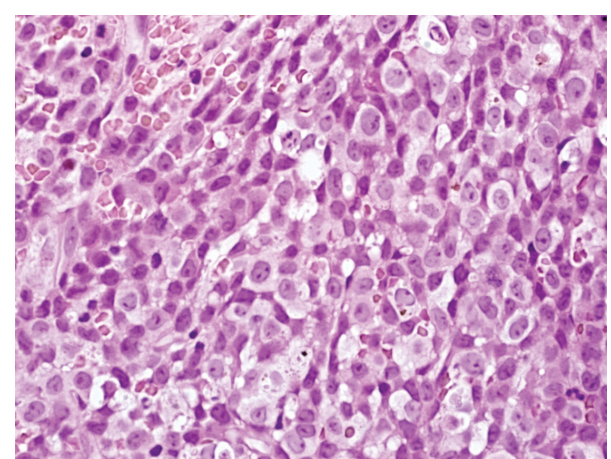

(d)

FIGURE 2: (a) Bone marrow aspirate showing necrotic cells with very rare intact cells. Note intense blue staining of necrotic cells. (b) Bone marrow trephine biopsy showing massive necrosis. Note the homogeneous staining of the necrotic marrow. (c) BM biopsy shows hypercellular marrow due to a diffuse abnormal malignant infiltrate with starry-sky appearance. Note that areas of necrosis are still present. (d) The neoplastic cells show atypical large lymphoid cells with round, slightly irregular, or indented nuclei, dispersed chromatin, abundant agranular cytoplasm, and prominent nucleoli (blast-like cells).

Medical Systems) and showed positivity for CD45, CD20, cyclin D1, and PAX 5 while CD3, CD5, CD23, bcl-2, and bcl-6 were negative (data not shown).

In $60 \%$ of cells, cytogenetic analysis revealed complex chromosomal abnormalities and chromosomal rearrangements in addition to the $\mathrm{t}(11 ; 14)$ (q13;q32) translocation (Figure 4(a)). FISH was performed on interphase cells using Vysis LSI IgH/CCND1 dual color, dual fusion probe (Abbott Laboratories, Abbott Park, IL), and confirmed IgH/CCND1 fusion in $44 \%$ of analyzed cells (Figure 4(b)). Cytogenetic investigations were reported as follows: 46,XY, $\operatorname{der}(1) \operatorname{inv}(1)(\mathrm{p} 32 \mathrm{q} 31) \operatorname{del}(1)(\mathrm{p} 13 \mathrm{p} 32)$ [5]/46,XY,sl,t(11;14)(q13; q32)[4]/40,sdl1,-8, der(13)t(13;13)(q12;q34),-13,del(15)(q22), $\operatorname{der}(16) t(16 ; ?)(p 11.2 ;$ ? $),-16,-17,-18,-19[2] / 46, X Y[9]$. nuc ish (CCND1x3), (IGHx3), (CCND1 con IGHx2) [44/100].

The patient received combination chemotherapy CHOP$\mathrm{R}$ (cyclophosphamide, adriamycin, vincristine, prednisone, and rituximab). His condition improved with a long-term survival rate (42 months at the time of publication).

\section{Discussion}

MCL is a clinically aggressive CD5+ B-cell neoplasm. It is highly associated with the $\mathrm{t}(11 ; 14)$ (q13; $\mathrm{q} 32)$ abnormality resulting in deregulated cyclin D1 expression $[10,11]$.
Although the features of blastic or large cell MCL have each been well described in the literature [12-14], our case of blastic MCL presented with predominant marrow involvement, extensive marrow necrosis without peripheral blood involvement, and without significant adenopathy or HSM. When BM examination represents the initial diagnostic procedure, it requires heightened awareness and the application of ancillary immunologic and molecular techniques. The presence of CCND1 gene rearrangements or cyclin D1 abnormalities should be assessed in such cases to establish the diagnosis of mantle cell lymphoma and exclude other CD5-/CD10- mature B-cell neoplasms.

MCL patients are predominantly male (ratio of $2: 1$ or greater) and have a median age at diagnosis of 60-65 years. Most patients initially present with stages III-IV, which is similar to what was seen in our case [2,9]; however, our case was unique in its presentation with the absence of lymphadenopathy and extranodal involvement which is usually present in MCL patients [1].

In our case, diagnostic problems were encountered due to massive $\mathrm{BM}$ necrosis without viable cells in the first $\mathrm{BM}$ examination and unusual clinical presentation with atypical immunophenotypic characteristics and morphologic features in the repeated BM. This prompted initial consideration of acute leukemia, although the immature cell markers CD34, 

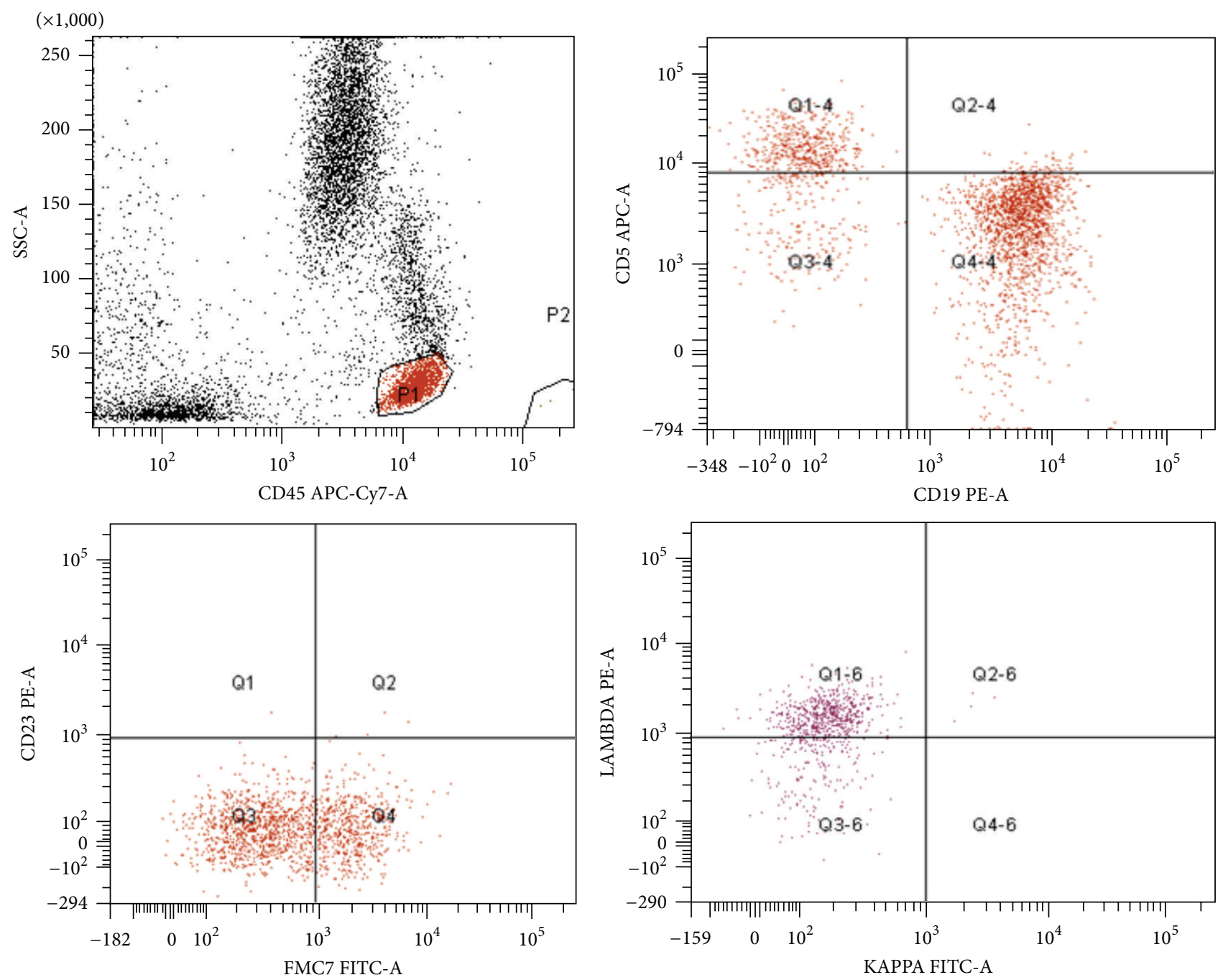

Figure 3: Flow cytometry analysis using side scatter/CD45 gating strategy; the gated population of cells (red) show bright CD45 positivity with expression of CD19 and FMC7 (45\%) monotypic lambda light chain. These cells were negative for CD10, CD5, CD23, and CD34.

CD10, and TdT were negative. Moreover, there was no access to histology because of no significant lymphadenopathy, organomegaly, or masses. These results are very similar to those of other reported studies $[15,16]$. It is recognized that the histologic diagnosis of MCL, particularly in nonnodal cases, may be difficult and that bone marrow histology is not always diagnostically conclusive $[17,18]$.

It has been shown that approximately $94 \%$ of MCL cases carry other karyotypic abnormalities in addition to the $t(11 ; 14)$. In most of these studies, $\operatorname{del}(13)$ (q14) was identified as the most frequent abnormality, followed by chromosome 1. Other common abnormalities that have been reported involve chromosomes 3, 6, 9, and 17 [5-7, 19-21].

The $t(11 ; 14)$ translocation is very specific to MCL among other B-NHL and is detected by conventional cytogenetics in $60-75 \%$ of MCL cases or by FISH in nearly $100 \%$ of MCL cases. Although the presence of the $t(11 ; 14)$ is the hallmark of MCL, it is believed that the resulting overexpression of cyclin D1 is not sufficient to cause a malignant transformation of lymphoid cells on its own. Additional chromosomal aberrations that have been identified in the majority of MCL patients might be the other factors necessary for lymphomagenesis [19, 22, 23], but the significance of these chromosomal abnormalities found in MCL has not been examined extensively $[4,23,24]$.

As reported in the literature, CD5- MCL is a diagnostic problem due to its rarity [25]. The ability to distinguish MCL from other B-cell lymphomas is extremely important because of the differences in the treatment options and in the clinical course [26]. Cytogenetic studies confirm the presence of $t(11 ; 14)$ with a complex karyotype. These findings highlight the importance of using ancillary techniques such as molecular and cytogenetic studies in such cases to establish the diagnosis.

\section{Conclusions}

Our case study may be reported as a unique case of CD5 negative blastic MCL with massive bone marrow necrosis 


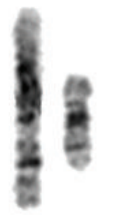

(1)

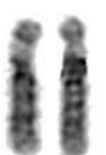

(6)

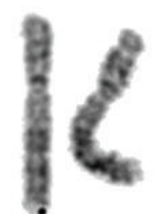

(2)

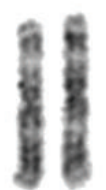

(3)

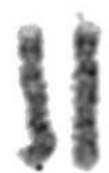

(4)

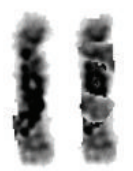

(5)

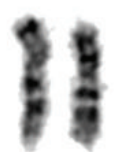

(7)

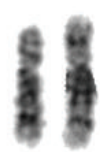

(8)

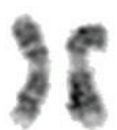

(9)

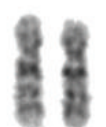

(10)

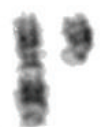

(11)

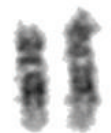

(12)

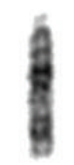

(13)

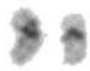

(19)
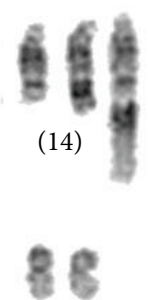

(20)

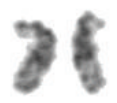

(15)

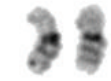

(16)

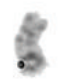

(17)

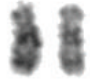

(18)

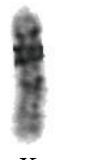

(21)

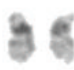

(22)

(a)

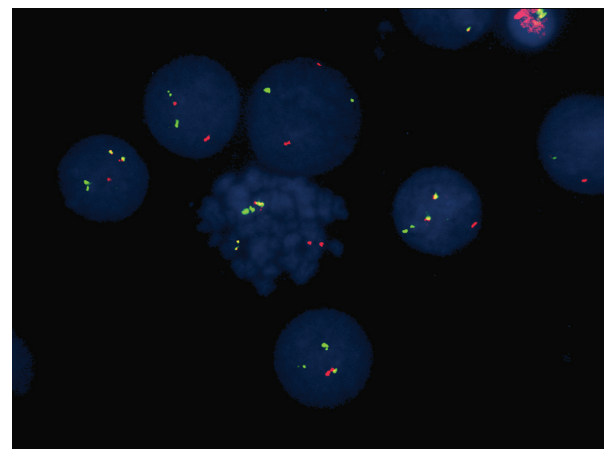

(b)

FIGURE 4: (a) Karyotypic analysis showing complex chromosomal abnormalities including translocation t(11;14). (b) FISH using IGH-CCND dual color dual fusion on interphases and metaphases cells showed the presence of the translocation $\mathrm{t}(11 ; 14)$.

as an initial feature without significant lymphadenopathy or HSM. These unusual findings made the diagnosis of MCL difficult. This study also highlights the importance of using ancillary techniques such as flow cytometry and molecular and cytogenetic studies to establish the diagnosis and differentiate different types of lymphomas in such cases. Most studies of MCL report karyotypic abnormalities in addition to the $t(11 ; 14)$, but the significance of these chromosomal abnormalities found in MCL has not been examined extensively and they might be factors necessary for lymphomagenesis.

\section{Abbreviations}

WHO: The World Health Organization

MCL: Mantle cell lymphoma

NHL: Non-Hodgkin's lymphoma
HSM: Hepatosplenomegaly

FISH: $\quad$ Fluorescent in situ hybridization

CHOP-R: Cyclophosphamide, adriamycin, vincristine, prednisone, and rituximab

PB: $\quad$ Peripheral blood

BM: $\quad$ Bone marrow

IHC: Immunohistochemistry.

\section{Conflict of Interests}

The authors declare that they have no competing interests.

\section{Authors' Contribution}

Ali Matar Alzahrani and Ghaleb Elyamany conceived and designed the study. Ghaleb Elyamany, Hatem Elghezal, and 
Hassan Aljasem analyzed the data. Ghaleb Elyamany wrote the first draft of the paper. Hatem Elghezal, Sultan Alotaibi, Eman Al Mussaed, and Hassan Aljasem contributed to the writing of the paper results and conclusions. Ghaleb Elyamany, Ali Matar Alzahrani, Eman Al Mussaed, Hatem Elghezal, and Sultan Alotaibi jointly developed the structure and arguments for the paper. Ghaleb Elyamany, Ali Matar Alzahrani, and Hatem Elghezal made critical revisions and approved final version. All authors reviewed and approved the final paper.

\section{Acknowledgments}

The authors would like to thank Staci Johnston, Premedical Student at Armstrong State University, Savannah, GA, USA, for editing this research article. Also, they thank Waleed ALBissi, Lab Administrator, and Mohamed Habibullah from Histopathology Division for their technical help in this study.

\section{References}

[1] N. S. Andersen, M. K. Jensen, P. de Nully Brown, and C. H. Geisler, "A Danish population-based analysis of 105 mantle cell lymphoma patients: Incidences, clinical features, response, survival and prognostic factors," European Journal of Cancer, vol. 38, no. 3, pp. 401-408, 2002.

[2] J. M. Vose, "Mantle cell lymphoma: 2013 update on diagnosis, risk-stratification, and clinical management," American Journal of Hematology, vol. 88, no. 12, pp. 1082-1088, 2013.

[3] S. H. Swerdlow, E. Campo, N. L. Harris et al., WHO Classification of Tumours of Haematopoietic and Lymphoid Tissue, IARC WHO Classification of Tumours, World Health Organization, 4th edition, 2008.

[4] A. Navarro and E. Campo, "II. New perspectives and challenges in the understanding of mantle cell lymphoma," Annals of Oncology, vol. 22, no. supplement 4, pp. iv32-iv35, 2011.

[5] I. Salaverria, A. Zettl, S. Beà et al., "Specific secondary genetic alterations in mantle cell lymphoma provide prognostic information independent of the gene expression-based proliferation signature," Journal of Clinical Oncology, vol. 25, no. 10, pp. 12161222, 2007.

[6] C. Royo, I. Salaverria, E. M. Hartmann, A. Rosenwald, E. Campo, and S. Beà, "The complex landscape of genetic alterations in mantle cell lymphoma," Seminars in Cancer Biology, vol. 21, no. 5, pp. 322-334, 2011.

[7] M. Onciu, E. Schlette, L. J. Medeiros, L. V. Abruzzo, M. Keating, and R. Lai, "Cytogenetic findings in mantle cell lymphoma: cases with a high level of peripheral blood involvement have a distinct pattern of abnormalities," American Journal of Clinical Pathology, vol. 116, no. 6, pp. 886-892, 2001.

[8] A. Goy and B. Kahl, "Mantle cell lymphoma: the promise of new treatment options," Critical Reviews in Oncology/Hematology, vol. 80, no. 1, pp. 69-86, 2011.

[9] M. Ghielmini and E. Zucca, "How I treat mantle cell lymphoma," Blood, vol. 114, no. 8, pp. 1469-1476, 2009.

[10] E. Campo, M. Raffeld, and E. S. Jaffe, "Mantle cell lymphoma," Seminars in Hematology, vol. 36, no. 2, pp. 115-127, 1999.

[11] H. Samaha, C. Dumontet, N. Ketterer et al., "Mantle cell lymphoma: a retrospective study of 121 cases," Leukemia, vol. 12, no. 8, pp. 1281-1287, 1998.
[12] M. M. Ott, G. Ott, R. Kuse et al., "The anaplastic variant of centrocytic lymphoma is marked by frequent rearrangements of the bcl-1 gene and high proliferation indices," Histopathology, vol. 24, no. 4, pp. 329-334, 1994.

[13] M. C. Zoldan, G. Inghirami, Y. Masuda et al., "Large-cell variants of mantle cell lymphoma: cytologic characteristics and p53 anomalies may predict poor outcome," British Journal of Haematology, vol. 93, no. 2, pp. 475-486, 1996.

[14] P. Lardelli, M. A. Bookman, J. Sundeen, D. L. Longo, and E. S. Jaffe, "Lymphocytic lymphoma of intermediate differentiation: morphologic and immunophenotypic spectrum and clinical correlations," The American Journal of Surgical Pathology, vol. 14, no. 8, pp. 752-763, 1990.

[15] T. P. Singleton, M. M. Anderson, C. W. Ross, and B. Schnitzer, "Leukemic phase of mantle cell lymphoma, blastoid variant," American Journal of Clinical Pathology, vol. 111, no. 4, pp. 495500, 1999.

[16] D. S. Viswanatha, K. Foucar, B. R. Berry, R. D. Gascoyne, H. L. Evans, and C. P. Leith, "Blastic mantle cell leukemia: an unusual presentation of blastic mantle cell lymphoma," Modern Pathology, vol. 13, no. 7, pp. 825-833, 2000.

[17] P. L. Cohen, P. J. Kurtin, K. A. Donovan, and C. A. Hanson, "Bone marrow and peripheral blood involvement in mantle cell lymphoma," British Journal of Haematology, vol. 101, no. 2, pp. 302-310, 1998.

[18] J. Wasman, N. S. Rosenthal, and D. C. Farhi, "Mantle cell lymphoma: morphologic findings in bone marrow involvement," American Journal of Clinical Pathology, vol. 106, no. 2, pp. 196200, 1996.

[19] I. Wlodarska, S. Pittaluga, A. Hagemeijer, C. de Wolf-Peeters, and $\mathrm{H}$. van den Berghe, "Secondary chromosome changes in mantle cell lymphoma," Haematologica, vol. 84, no. 7, pp. 594599, 1999.

[20] B. Espinet, F. Solé, S. Woessner et al., "Translocation $(11 ; 14)(q 13 ; q 32)$ and preferential involvement of chromosomes 1, 2, 9, 13, and 17 in mantle cell lymphoma," Cancer Genetics and Cytogenetics, vol. 111, no. 1, pp. 92-98, 1999.

[21] M. Bentz, A. Plesch, L. Bullinger et al., " $t(11 ; 14)$-positive mantle cell lymphomas exhibit complex karyotypes and share similarities with B-cell chronic lymphocytic leukemia," Genes Chromosomes and Cancer, vol. 27, no. 3, pp. 285-294, 2000.

[22] A. Cuneo, R. Bigoni, G. M. Rigolin et al., "Cytogenetic profile of lymphoma of follicle mantle lineage: correlation with clinicobiologic features," Blood, vol. 93, no. 4, pp. 1372-1380, 1999.

[23] S. Sander, L. Bullinger, E. Leupolt et al., "Genomic aberrations in mantle cell lymphoma detected by interphase fluorescence in situ hybridization. Incidence and clinicopathological correlations," Haematologica, vol. 93, no. 5, pp. 680-687, 2008.

[24] F. Rubio-Moscardo, J. Climent, R. Siebert et al., "Mantle-cell lymphoma genotypes identified with CGH to BAC microarrays define a leukemic subgroup of disease and predict patient outcome," Blood, vol. 105, no. 11, pp. 4445-4454, 2005.

[25] N. Golardi, M. R. Velasco, and M. T. Elghetany, "Marginal zone variant of mantle cell lymphoma: CD5-negative cyclin D1-positive variant posing a diagnostic dilemma," Pathology International, vol. 59, no. 5, pp. 317-321, 2009.

[26] Z. Liu, H. Y. Dong, W. Gorczyca et al., "CD5- mantle cell lymphoma," The American Journal of Clinical Pathology, vol. 118, no. 2, pp. 216-224, 2002. 


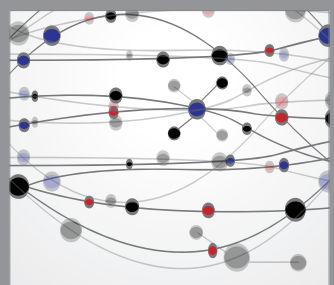

The Scientific World Journal
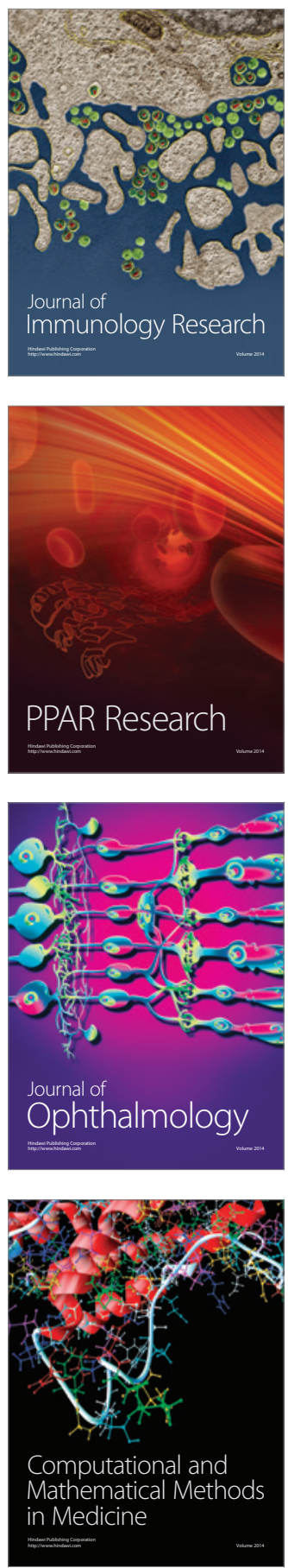

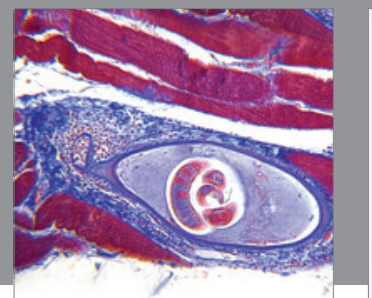

Gastroenterology

Research and Practice
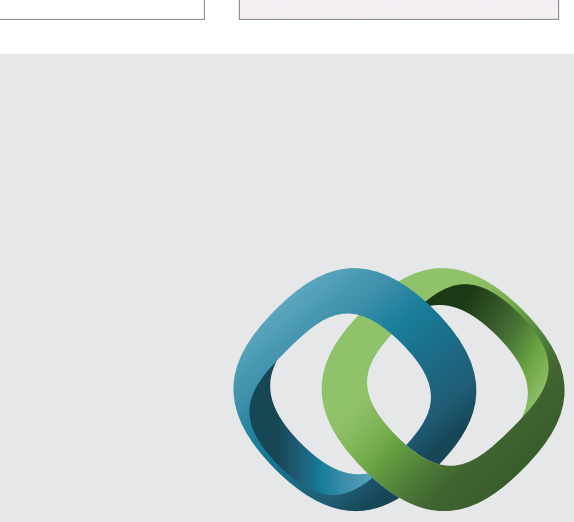

\section{Hindawi}

Submit your manuscripts at

http://www.hindawi.com
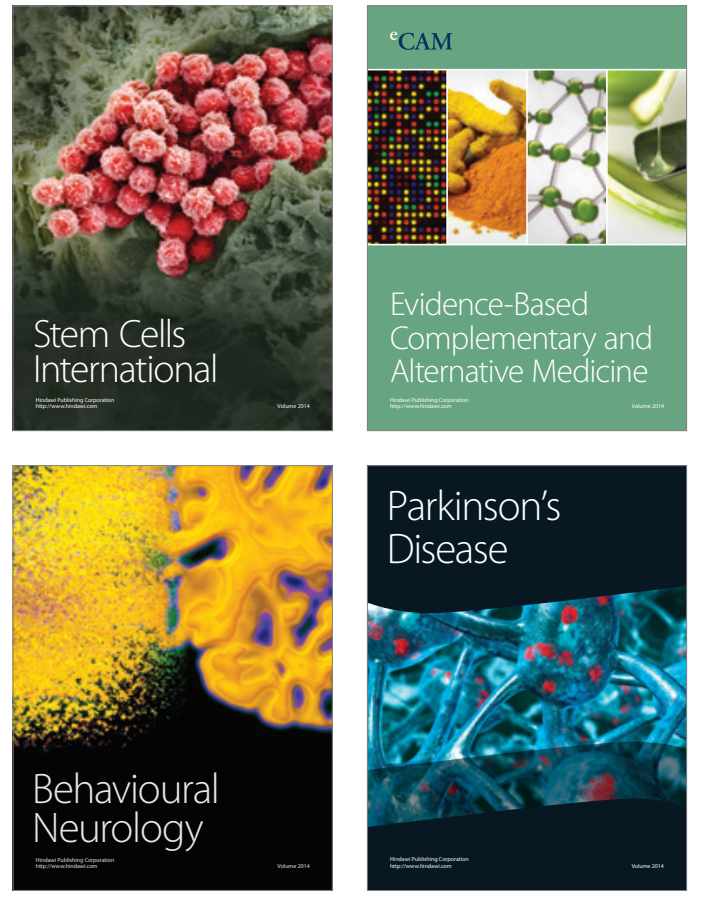
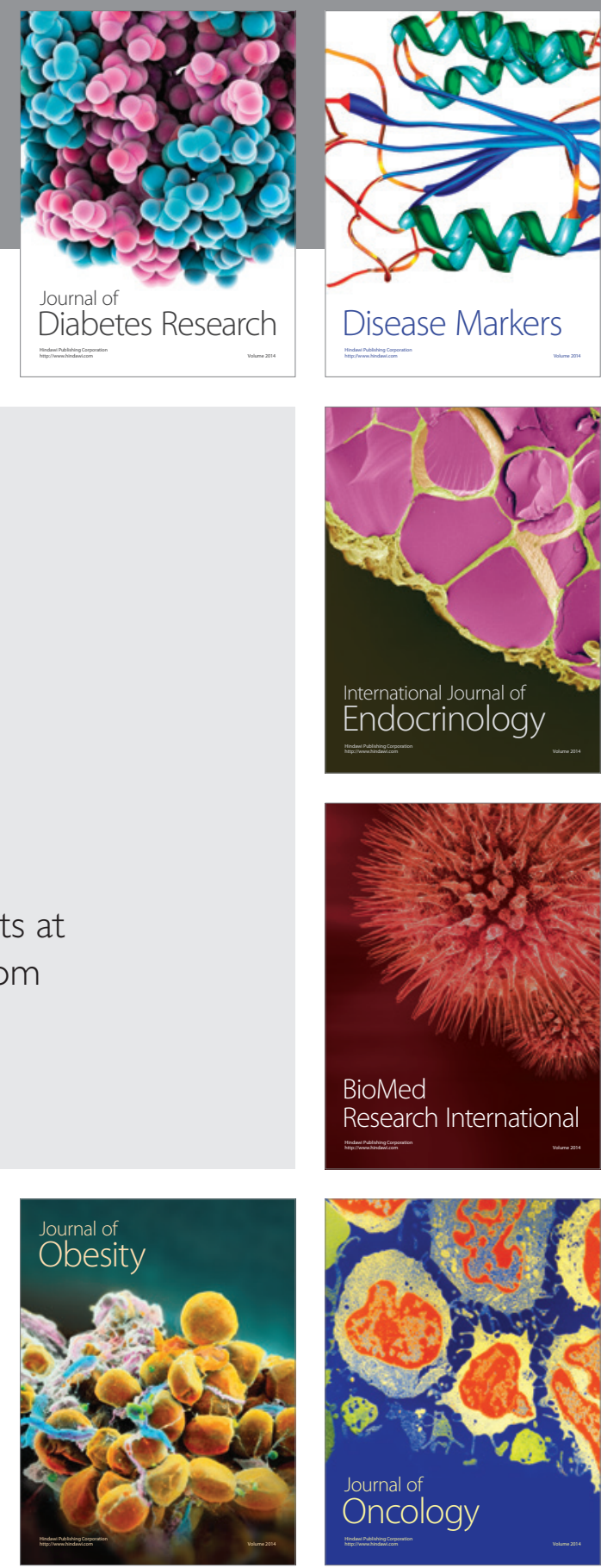

Disease Markers
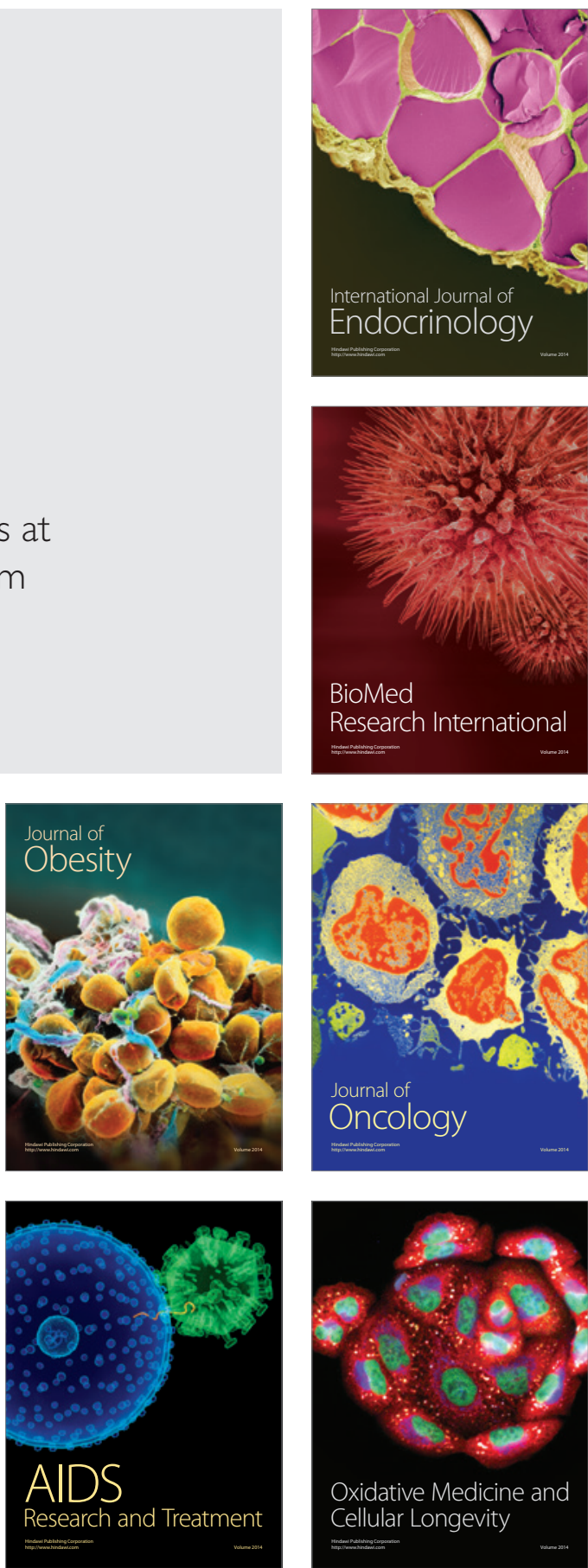